\title{
Syphilis, Hepatitis C and HIV in Eastern Europe
}

Heather Bailey ${ }^{1}$

Anna Turkova ${ }^{2}$

Claire Thorne ${ }^{1}$

1. Population, Policy and Practice Programme, University College London (UCL) Great Ormond Street Institute of Child Health, UCL

2. Medical Research Council Clinical Trials Unit at University College London

\section{Corresponding Author:}

Name: Dr Claire Thorne

Address:

Population, Policy and Practice Programme, University College London (UCL) Great Ormond Street Institute of Child Health, UCL, 30 Guilford Street, London WC1N 1EH

Tel: 02079052105

Email: claire.thorne@ucl.ac.uk

This is not the final published version. The final published version can be found at:

Syphilis, hepatitis $\mathrm{C}$ and HIV in Eastern Europe Bailey, Heather; Turkova, Anna; Thorne, Claire Current Opinion in Infectious Diseases:

February 2017 - Volume 30 - Issue 1 - p 93-100

doi: 10.1097/QCO.0000000000000326

SEXUALLY TRANSMITTED DISEASES: Edited by Karen E. Rogstad 


\begin{abstract}
Purpose of review:

Eastern Europe and Central Asia (EECA) has experienced large-scale epidemics of syphilis, HCV and HIV over the past few decades. Here, we review recent evidence on the epidemiology of and the response to these intersecting epidemics.
\end{abstract}

Recent findings:

The HIV epidemic in EECA continues to expand, with new infections increasing by $>50 \%$ between 2010 and 2015. HCV is now in the top 10 causes of death in EECA, with Russia accounting for more than half of the global burden of HCV infections, but access to direct-acting antivirals remains a major obstacle for control of the epidemic. Although syphilis incidence is generally declining, high prevalence is reported in key populations, particularly sex workers and people who inject drugs. Recent epidemiological studies have highlighted very high prevalence of HIV, syphilis and HCV in prison populations, alongside poor access to prevention and treatment.

Summary:

Multiple factors are contributing to the ongoing and overlapping HIV, HCV and syphilis epidemics in EECA, including low coverage with antiretroviral therapy and insufficient scale of prevention services. Further research is required to estimate the burden of infections and identify effective prevention and treatment strategies in hard-to-reach key populations, particularly men who have sex with men.

Keywords (3-5):

HIV, HCV, syphilis, epidemiology, Eastern Europe

Word count: 2628 (excluding key points) 
Abbreviations:

ART Antiretroviral therapy

CA Central Asia

DAA Direct acting antivirals

DALY Disability adjusted life year

EE Eastern Europe

EECA Eastern Europe and Central Asia

FSW Female sex workers

HCV Hepatitis C virus

HIV Human immunodeficiency virus

IDU Injecting drug use

MSM Men who have sex with men

MTCT Mother-to-child transmission

NSP Needle and syringe programmes

OST Opioid substitution therapy

PWID People who inject drugs

STI Sexually transmitted infection

TB Tuberculosis

WHO World Health Organization 


\section{Introduction}

Eastern Europe and Central Asia (EECA) is a socioeconomically and geopolitically diverse region that, following the break-up of the Soviet Union, has experienced intersecting epidemics of sexually transmitted infections (STIs) (particularly syphilis), HIV, HCV and tuberculosis (TB), reflecting major socio-economic changes, disruption to public health systems and increased risk behaviours [1-6]. Injecting drug use (IDU) is highly prevalent in parts of the region and has been a key driver of these epidemics $[1,2,7]$. Eastern and South Eastern Europe has the highest prevalence of IDU in the world, at $1.27 \%$ of the population aged $15-64$ years, versus $0.25 \%$ globally, with almost all the people who inject drugs (PWID) in this region living in Russia and Ukraine [8].

EECA is one of only two regions in the world where HIV incidence is increasing, with new infections increasing by $>50 \%$ between 2010 and 2015 [9]. This reflects a high proportion of undiagnosed individuals, low treatment coverage (on a regional basis, $21 \%$ overall and $31 \%$ among those diagnosed [10]) and insufficient and/or ineffective harm reduction and prevention services [11,12]. The latter is especially an issue in Russia, Tajikistan and Turkmenistan which ban the use of opioid substitution therapy (OST) for PWID, and regional coverage of PWID with OST is < $1 \%$ [11-14].

Our aim is to summarize recent evidence on the inter-related epidemics of HIV, HCV and syphilis in the EECA region (i.e. the eastern part of the WHO European Region).

HIV

Around $90 \%$ of people living with HIV in EECA are in Russia and Ukraine, with Russia currently accounting for over $80 \%$ of new HIV cases each year [10]. Over half of new infections in Russia in 2014 were in PWID [15]; the contribution of limited harm reduction and poor ART coverage to ongoing HIV incidence in this group is highlighted by recent modelling work, which estimated that coverage of OST, needle and syringe programmes (NSP) and ART at only $14 \%$ would reduce HIV incidence by $30 \%$ over 10 years among PWID in St Petersburg [16]. Rates of incarceration are very 
high overall in EECA, for example 445 per 100,000 in Russia vs median 84 per 100,000 in Western Europe [17], with PWID often incarcerated for minor drug offences resulting in much higher HIV prevalence among prison populations than the surrounding community [11]). A recent Lancet series article explored the central role that prisons play in intensifying and perpetuating the overlapping epidemics of HIV alongside HCV, STIs, TB and substance use disorders in EECA [11]; estimates of HIV prevalence in prisons ranged from $<2.5 \%$ in Tajikistan and Armenia to $19.4 \%$ in Ukraine and $20.4 \%$ in Latvia. Recent studies with data on policing and prisons as components of the HIV risk environment in EECA are given in Table 1.

Sexual transmissions, commonly in bridging populations e.g. sex partners of PWID, contribute a substantial proportion of new HIV cases and particularly among women; official figures indicate that 40\% of HIV infections in Russia overall in 2014 were heterosexually acquired [15] and 66\% in Ukraine in 2013 [26]. Antenatal HIV prevalence is declining in Ukraine (0.33\% in 2015) [27] but increasing in Russia (0.75\% in 2013 [15]) with around 4000 and 15,000 HIV-exposed infants born each year respectively and mother-to-child transmission rates of $3-4 \%[28,29]$. Intensely discriminatory and punitive legal environments for men who have sex with men (MSM) [30] and PWID [11] in EECA contribute to some misclassification of infections from these groups as heterosexual. A recent study triangulating serosurvey data against MSM population size in Ukraine estimated that only $5 \%$ of HIV cases among MSM were correctly classified, with MSM and PWID constituting up to $8 \%$ and $35 \%$ of the male "heterosexual" category respectively [31]. In Kiev, of 191 men identifying as MSM and accessing HIV testing in 2013-14, a quarter tested positive giving a diagnosis rate of 516-1548 per 100,000 , up to 20 times higher than national figures which indicated only 900 infections in MSM up to 2013 [32]. Criminalisation and stigmatisation of MSM are important barriers to coverage of HIV prevention services and HIV testing and treatment in this group $[25,30]$. A recent randomised trial in 18 MSM social networks in Russia and Hungary assessed a novel sexual risk reduction intervention (i.e. training of network leaders to deliver prevention advice to other members) versus standard 
HIV/STI counselling; although there were reduced high risk behaviours and lower incidence of new HIV/STI in the interventional arm (9\% vs 15\%), statistical significance was not achieved [33].

Clustering of risk factors for HIV among female sex workers (FSW) is well recognised [21,34], with HIV prevalence up to $13-14 \%$ among FSW in some regions in Ukraine [26]. Recent data from around 3500 men undergoing HIV testing in St Petersburg and Leningrad indicate a similar clustering of risk in FSWs' clients: history of IDU was independently associated with having sex with a PWID and having purchased sex services [35]. Of the $64 \%$ of men in this study who reported not using condoms during last sexual contact, two-thirds had $\geq 1$ additional risk factor for HIV acquisition (multiple or casual sex partners, or use of commercial sex worker services). Labour migrants from Central Asia are at high risk of HIV acquisition due to contact with FSW, and are an important bridging population in their home countries [5]; in a recent study among 510 prisoners in Azerbaijan, those who had worked in Russia or Ukraine remained at increased risk of HIV after adjusting for unprotected sex and IDU [23].

AIDS deaths are escalating in EECA, from 38,000 in 2010 to 47,000 in 2015 [9]. This partly reflecting the large "break-points" in the first steps in the cascade of care describing progress towards UNAIDS 90:90:90 targets for 2020 (90\% infected diagnosed; 90\% diagnosed on treatment; $90 \%$ treated with undetectable viral load). In Ukraine in 2015, only an estimated 58\% of individuals with HIV were diagnosed and 45\% linked to care [9] (56\% and 43\% respectively in Russia in 2014)[12], and late diagnosis with advanced immunosuppression is common, reflecting poor effectiveness of HIV testing strategies. A study among MSM in Moscow indicated even greater losses in the cascade among this marginalised group, with only $13 \%$ diagnosed and $9 \%$ linked to care [36]. TB is a major contributor to AIDS deaths due to an epidemic of multi-drug resistant TB, poor ART coverage, poor TB care (including lack of susceptibility testing and use of suboptimal regimens containing $<3$ active drugs) and late diagnosis of HIV and/or TB with advanced immunodeficiency and disseminated disease $[37,38]$. A recent study including $834 \mathrm{HIV} / \mathrm{TB}$ co-infected people in EE, 317 in Western Europe and 
255 in Latin America found that around 40\% in EE had multi-drug resistant TB, and probability of death in the 12 months following TB diagnosis was $29 \%$ (versus $4 \%$ in Western Europe and $11 \%$ in Latin America) [38]. Lack of integration of HIV and TB services is an important structural barrier to improvement of outcomes in EE $[39,40]$. Other service-level barriers to HIV care identified in a qualitative study in Russia related to problems accessing care, dissatisfaction with the quality of services and negative attitudes of healthcare workers [41].

Recent data from a cluster randomised clinical trial among PWID in Ukraine demonstrated the value of peer interventions to reach marginalised high-risk groups, with a peer leader network intervention associated with a $47 \%$ reduced hazard of HIV acquisition when compared with standard testing and counselling [42]. Innovative interventions to reach key populations most affected by the HIV epidemic in EE with prevention, testing and treatment services are urgently needed. However, services for HIV-positive people and particularly PWID in Ukraine have been severely disrupted by the recent conflict, in which >1.7 million people had been displaced [43], healthcare services interrupted [28] and OST programmes abruptly halted in occupied territories [44,45].

\section{Hepatitis C}

EECA is among the global regions with the highest HCV infection rates. An estimated 6.6 to 9.5 million people live with viraemic infection in the region [46,47], accounting for $2.3 \%$ prevalence among general populations, twice as high compared to global estimates (Table 2). The epidemic is diverse in the region with HCV viraemia ranging widely from $0.9 \%$ in Belarus and $1.7 \%$ in Latvia to 4.4\% in Uzbekistan [47]. Russia has the highest absolute number of infections and is one of the six countries in the world (together with Egypt, China, India, Nigeria and Pakistan) accounting for more than half of the global burden [47].

The recent Global Burden of Disease Study estimated global mortality attributable to viral hepatitis has increased since 1990 [48]. In 2013 alone, HCV accounted for over 38000 deaths and over a 
million of disability adjusted life years (DALYs) in EECA (Table 2), and became the $10^{\text {th }}$ and the $4^{\text {th }}$ leading cause of death in EE and CA respectively $[48,49]$.

The most common genotype in the region is $1 b$, accounting for two-thirds of all infections ranging from $53.5 \%$ in Belarus to $87.7 \%$ in Latvia; it is followed by genotype 3 with a wide range from $7.7 \%$ in Tajikistan to $38.5 \%$ in Belarus $[47,49]$. There is some data showing that genotype 3 is more common in PWID in Russia, with genotype $1 \mathrm{~b}$ more common in the general population and in dialysis patients [50].

IDU is a major driving force for the HCV epidemic in EECA. PWID have estimated HCV-seroprevalence 20 times higher than the general population, accounting for 1.5 million people with chronic infections in the region [46]. In Russia, Ukraine and Georgia, HCV seroprevalence in PWID as high as $71-90 \%$ were reported, accounting for $22-40 \%$ of the total HCV burden in these countries [51]. With the highest rate of incarceration of PWID and other at risk groups [11], EECA has one of the highest estimated HCV seroprevalence in prisoners at $20.2 \%(95 \% \mathrm{Cl} 11.8-30.1)[52]$. However, recent studies in prisons have reported even higher HCV seroprevalence in some countries (Table 1).

Other key populations at high risk are MSM and sex workers with an estimated HCV-seroprevalence nearly twice and five times as high as in general population respectively [46]. No recent studies on HCV seroprevalence in MSM in EECA have been published; in a 2013 publication, HCV seroprevalence was $4.5 \%$ in a biobehavioural surveillance study in Moldova [53].

Access to testing and treatment remains a major obstacle for control of the HCV epidemic in EECA. New direct-acting antivirals (DAAs) with over $90 \%$ cure rates and minimal side-effects provide a great promise, but costs remain prohibitive, particularly for middle-income countries with no access to generic drugs. In a recent review, estimated treatment uptake in 2013 ranged only from 0.1 to $0.5 \%$ among the general HCV viraemic population [51]. PWID remain largely excluded from national programs [54], despite being the most affected population and the most cost-effective group to treat [55]. In Russia, Ukraine and Georgia, PWID accounted for $<1 \%, 10-20 \%$ and $20-30 \%$ of all 
treated persons respectively [51]. Martin et al, in their modelling analyses showed that treatment of PWID with DAAs in conjunction with high-coverage NSP and OST can substantially reduce HCV prevalence in the general population $[55,56]$. Regionally, there is no HCV treatment provided in prisons, with the exception of Georgia [11].

\section{HIV-HCV Coinfection}

Overlapping transmission routes for HIV and HCV explain the high rate of HIV-HCV coinfection in EECA with the highest HCV prevalence in HIV-infected PWID (median 83\%, IQR 56-98\%)[57]. Recent estimates suggest that EECA accounts for $27 \%$ of the global burden of co-infection (median 607,700 co-infected persons, IQR 404,100-746,500)[57]. Data on HIV-HCV coinfection prevalence in populations other than PWID are limited in EECA, particularly for MSM. A recent study of around 1500 childbearing women (recently delivered) with HIV living in Ukraine reported that $33.5 \%$ had HCV co-infection, with $20 \%$ reporting an IDU history [58].

Co-infection leads to accelerated progression to final stages of liver disease, hepatocellular carcinoma and increased mortality [59], with a profound impact in EECA where access to treatment of both infections is challenging, especially for key populations. In a recent study of HIV/HCV coinfected children and young people from across Europe, among those from EE, only $31 \%$ had been treated with pegylated interferon/ribavirin (6/67 in Ukraine and 30/49 in Russia) and less than 50\% achieved sustained virological response [60]. Ukraine is a notable exception, where a recent project launched by International HIV/AIDS alliance aims to treat 1500 patients from most vulnerable populations, including PWID, PWID HIV-infected partners and commercial sex workers, with sofosbuvir-based regimens. They showed excellent retention in care and adherence to treatment and high rates of successful outcomes in the initial stage of the project [61].

\section{Syphilis}


EE includes some regions that historically were hyper-endemic for syphilis, but syphilis incidence has been declining following the major epidemic in the 1990s [3]. A recent analysis of Russian data showed that incidence declined nationally from 79.4 per 100,000 in 2004 to 28.9 per 100,000 in 2013, but remains high in some regions, particularly the Far Eastern, Siberian and Northwestern Federal districts [62]. These declines in Russia are occurring against a backdrop of increasing syphilis incidence in the EU/EEA, mainly driven by MSM, although even the highest incidence countries have considerably lower rates than Russia (e.g. 7.2 and 7.7 per 100,000 in UK and Spain respectively)[63].

The first molecular epidemiological study of syphilis in EE was recently conducted, in the Tuva Republic, in southern Siberia: the authors estimated an incidence rate of 177 per 100,000 in 2013 and demonstrated that the $14 \mathrm{~d} / \mathrm{f}$ T.pallidum strain caused $91 \%$ of the syphilis cases [64]; this study also reported a $2.4 \%$ prevalence of macrolide-resistance (23S rRNA A2058G). A recent report from the Czech Republic has documented a substantial increase in macrolide-resistant strains (A2058G and A2059G 23S rRNA) over time $[65,66]$, consistent with findings from elsewhere in Europe and globally [67].

Knowledge of syphilis epidemiology depends on the national STI surveillance systems, which may incorporate case reporting by STI centres, monitoring of syphilis prevalence in pregnant women, congenital syphilis monitoring and bio-behavioural surveillance surveys in key populations. Recently published incidence and prevalence data for the general population, as well as for key populations are presented in Table 3. These systems may also monitor the proportion of early (i.e. primary, secondary and early latent syphilis) versus late (i.e. late latent and tertiary syphilis) cases. In Russia, an increase in the proportion of late forms of syphilis has been reported, from $1.2 \%$ in 2004 to $12 \%$ in 2013 [62]. This is of concern, as it may indicate issues with access to testing and treatment. 
Elimination of vertical transmission of syphilis was launched as a global target by the WHO in 2007 (alongside that for HIV). Maternal and congenital syphilis rates have declined, although in 2012 there were an estimated 102,000 new congenital infections worldwide [75]. A recent WHO Europe regional technical consultation noted that barriers to elimination of congenital syphilis in EE include poor access to antenatal care for women in key populations and unnecessary delays between antenatal diagnosis and treatment [76]. In June 2016, WHO validated elimination of MTCT of syphilis in Belarus and Moldova (i.e. $\geq 95 \%$ antenatal care coverage, $\geq 95 \%$ antenatal syphilis testing coverage, $\geq 95 \%$ treatment of seropositive women achieved over $\geq 2$ years, plus incidence of congenital syphilis $\leq 50$ cases per 100,000 livebirths achieved for $\geq 1$ year)[77].

\section{Conclusion}

The HIV, HCV and syphilis epidemics have highlighted the frailties of health care systems in EECA, and widespread stigma, denial and neglect of health problems of key populations. Screening, treatment and prevention strategies, focused on regional risk factors, need to be significantly strengthened as an estimated 2 million Russians will be HIV-positive by 2020 based on current trajectories. Progress towards the WHO target of eliminating $\mathrm{HCV}$ as a public health problem in the next 15 years and the UNAIDS 90:90:90 target by 2020 will only be possible with strong advocacy, political commitment, substantial financial investments and improvements in social justice and equity. 


\section{Key Points}

- The burden of HIV, HCV and syphilis infections in Eastern Europe and Central Asia is high, and partly reflects the high prevalence of injecting drug use in the region, with HIV and Hepatitis $\mathrm{C}$ among the 10 top mortality causes in the region

- Stigma and discrimination around these infections and the associated key populations (e.g. MSM, PWID, sex workers) are important barriers to access to care, treatment and prevention

- The proportion of people living with HIV on antiretroviral therapy is one of the lowest in the world, whilst access to new directly acting antivirals for treatment of HCV is challenging due to prohibitive costs for low-middle income countries, as most in EECA are excluded from voluntary licences

- The region's prisoners have amongst the highest HIV and HCV prevalence worldwide among incarcerated populations. Access to diagnosis and treatment for both infections and OST in prisons is largely non-existent or inadequately scaled to need.

- Data on prevalence of HIV, HCV and syphilis in MSM and sex workers are very limited

Financial support and sponsorship: Some of this work was undertaken at GOSH/UCL Institute of Child Health which received a proportion of funding from the UK Department of Health's NIHR Biomedical Research Centres funding scheme.

\section{Conflict of interest}

The authors have no conflicts of interest.

Acknowledgements: none 
1. Jolley E, Rhodes T, Platt L, et al. HIV among people who inject drugs in Central and Eastern Europe and Central Asia: a systematic review with implications for policy. BMJ Open 2012, 2.

2. Dehne KL, Khodakevich L, Hamers FF, Schwartlander B. The HIV/AIDS epidemic in eastern Europe: recent patterns and trends and their implications for policy-making. AIDS 1999, 13:741-749.

3. Tichonova L, Borisenko K, Ward H, et al. Epidemics of syphilis in the Russian Federation: trends, origins, and priorities for control. Lancet 1997, 350:210-213.

4. Cornberg M, Razavi HA, Alberti A, et al. A systematic review of hepatitis C virus epidemiology in Europe, Canada and Israel. Liver Int 2011, 31 Suppl 2:30-60.

5. Thorne C, Ferencic N, Malyuta R, et al. Central Asia: hotspot in the worldwide HIV epidemic. Lancet Infect Dis 2010, 10:479-488.

6. Hamers FF, Downs AM. HIV in central and eastern Europe. Lancet 2003, 361:1035-1044.

7. Heimer R, Eritsyan K, Barbour R, Levina OS. Hepatitis C virus seroprevalence among people who inject drugs and factors associated with infection in eight Russian cities. BMC Infect Dis 2014, 14 Suppl 6:S12.

8. United Nations Office on Drugs and Crime: World Drug Report, 2016. Edited by. Vienna: UNODC; 2016.

9. UNAIDS: UN Global AIDS Update 2016. Edited by. Geneva; 2016. [UNAIDS (Series Editor):

10. UNAIDS: Prevention Gap Report, available http://www.unaids.org/sites/default/files/media_asset/2016-prevention-gap-report_en.pdf. Accessed August 2016. Edited by; 2016.

11. Altice FL, Azbel L, Stone J, et al. The perfect storm: incarceration and the high-risk environment perpetuating transmission of HIV, hepatitis C virus, and tuberculosis in Eastern Europe and Central Asia. Lancet 2016. 
** Important paper with a systematic review of epidemiological, legal and treatment/care data, an assessment of the risk environment in the region and mathematical modelling approaches applied to Ukraine data.

12. Kazatchkine M. Drug use, HIV, HCV and TB: major interlinked challenges in Eastern Europe and Central Asia. J Int AIDS Soc 2014, 17:19501.

13. Degenhardt L, Mathers BM, Wirtz AL, et al What has been achieved in HIV prevention, treatment and care for people who inject drugs, 2010-2012? A review of the six highest burden countries. Int J Drug Policy 2014, 25:53-60.

14. Csete J, Kamarulzaman A, Kazatchkine M, et al. Public health and international drug policy. Lancet 2016, 387:1427-1480.

15. Okhonskaia L. HIV infection in children and women in Russia. In International Scientific-Practical Conference on Problems of Prevention of MTCT of HIV. Edited by. St Petersburg, Russia; 2015.

16. Vickerman P, Platt L, Jolley E, et al. Controlling HIV among people who inject drugs in Eastern Europe and Central Asia: insights from modeling. Int J Drug Policy 2014, 25:1163-1173.

17. Walmsley R: World Prison Population List, available http://www.prisonstudies.org/sites/default/files/resources/downloads/world_prison_popul ation_list_11th_edition.pdf. Accessed August 2016. Edited by; 2015.

18. Kutsa O, Marcus R, Bojko MJ, et al. Factors associated with physical and sexual violence by police among people who inject drugs in Ukraine: implications for retention on opioid agonist therapy. J Int AIDS Soc 2016, 19:20897.

19. Polonsky M, Azbel L, Wickersham JA, et al. Challenges to implementing opioid substitution therapy in Ukrainian prisons: Personnel attitudes toward addiction, treatment, and people with HIV/AIDS. Drug Alcohol Depend 2015, 148:47-55.

20. Shannon K, Strathdee SA, Goldenberg SM, et al. Global epidemiology of HIV among female sex workers: influence of structural determinants. Lancet 2015, 385:55-71. 
21. Wirtz AL, Peryshkina A, Mogilniy V, et al. Current and recent drug use intensifies sexual and structural HIV risk outcomes among female sex workers in the Russian Federation. Int J Drug Policy 2015, 26:755-763.

22. Azbel L, Polonsky M, Wegman M, et al. Intersecting epidemics of HIV, HCV, and syphilis among soon-to-be released prisoners in Kyrgyzstan: Implications for prevention and treatment. Int J Drug Policy 2016, 37:9-20.

** Important study of prisoners in Kyrgyzstan exploring prevalence of and risk factors for HIV, HCV and syphilis.

23. Azbel L, Wickersham JA, Wegman MP, et al. Burden of substance use disorders, mental illness, and correlates of infectious diseases among soon-to-be released prisoners in Azerbaijan. Drug Alcohol Depend 2015, 151:68-75.

24. Polonsky M, Azbel L, Wegman MP, et al. Pre-incarceration police harassment, drug addiction and HIV risk behaviours among prisoners in Kyrgyzstan and Azerbaijan: results from a nationally representative cross-sectional study. J Int AIDS Soc 2016, 19:20880.

25. Santos GM, Makofane K, Arreola S, et al. Reductions in access to HIV prevention and care services are associated with arrest and convictions in a global survey of men who have sex with men. Sex Transm Infect 2016.

26. Ministry of Health of Ukraine. Ukraine harmonized AIDS response progress report, Reporting period: January 2012 - December 2013, available at www.unaids.org/sites/default/files/...//UKR_narrative_report_2014.pdf. Edited by; 2014. 27. Martsynovska V. Modern Trends in the HIV Epidemic: Monitoring and evaluation at Centre for Disease Control, Ukrainian Ministry of Health. In HIV-positive youth in Ukraine: characteristics, outcomes and models of service provision. CIPHER project launch meeting, 17-18th March 2016; Kiev, Ukraine. Edited by. Kiev, Ukraine; 2016.

28. Ukrainian Centre of Socially Dangerous Disease Control of the Ministry of Health of Ukraine, Institute of Epidemiology and Infectious Diseases named after L. Gromashevskyi of the 
National Academy of Medical Sciences of Ukraine: HIV-infection in Ukraine, Bulletin No 43.

Edited by. Kiev; 2015.

29. Ministry of Health Russian Federation. Ministry of Health Russian Federation: National Report on Measures to Combat HIV/AIDS in 2014. Edited by; 2015.

30. Beyrer C, Baral SD, Collins C, et al. The global response to HIV in men who have sex with men. Lancet 2016, 388:198-206.

31. Cakalo JI, Bozicevic I, Vitek C, et al. Misclassification of men with reported HIV infection in Ukraine. AIDS Behav 2015, 19:1938-1940.

32. Simmons R, Malyuta R, Chentsova N, et al. HIV Testing and Diagnosis Rates in Kiev, Ukraine: April 2013-March 2014. PLoS One 2015, 10:e0137062.

*This study provide evidence that HIV infections in MSM are misclassified in official figures in Ukraine, and that there is a "hidden" epidemic in this group

33. Amirkhanian YA, Kelly JA, Takacs J, et al. Effects of a social network HIV/STD prevention intervention for MSM in Russia and Hungary: a randomized controlled trial. AIDS 2015, 29:583-593.

34. Decker MR, Wirtz AL, Moguilnyi V, et al. Female sex workers in three cities in Russia: HIV prevalence, risk factors and experience with targeted HIV prevention. AIDS Behav 2014, 18:562-572.

35. Girchenko P, Ompad DC, Kulchynska R, et al. Correlates of Lifetime History of Purchasing Sex Services by Men in Saint Petersburg and Leningrad Oblast, Russia. J Urban Health 2015, 92:1105-1116.

36. Wirtz AL, Zelaya CE, Latkin C, et al. The HIV care continuum among men who have sex with men in Moscow, Russia: a cross-sectional study of infection awareness and engagement in care. Sex Transm Infect 2016, 92:161-167. 
37. Efsen AM, Schultze A, Post FA, et al. Major Challenges in Clinical Management of TB/HIV Coinfected Patients in Eastern Europe Compared with Western Europe and Latin America. PLoS One 2015, 10:e0145380.

**Study exploring the predictors of multi-drug resistant TB and TB treatment in HIV-positive patients in Europe, highlighting important gaps in optimising TB treatment in EE

38. Podlekareva DN, Efsen AM, Schultze A, et al. Tuberculosis-related mortality in people living with HIV in Europe and Latin America: an international cohort study. Lancet HIV 2016, 3:e120131.

** Large pan-European study estimating one year mortality rates among HIV-positive patients diagnosed with TB in 2011-2013, reporting very high mortality in Eastern Europe linked with high prevalence of multi-drug resistant TB, sub-optimal TB treatment and other factors.

39. Lazarus JV, Laut KG, Safreed-Harmon K, et al. Disparities in HIV clinic care across Europe: findings from the EuroSIDA clinic survey. BMC Infect Dis 2016, 16:335.

40. Mansfeld M, Skrahina A, Shepherd L, et al. Major differences in organization and availability of health care and medicines for HIV/TB coinfected patients across Europe. HIV Med 2015, 16:544-552.

41. Kuznetsova AV, Meylakhs AY, Amirkhanian YA, et al. Barriers and Facilitators of HIV Care Engagement: Results of a Qualitative Study in St. Petersburg, Russia. AIDS Behav 2016, $20: 2433-2443$.

42. Booth R, Davis JM, Dvoryak S, et al. HIV incidence among people who inject drugs (PWIDs) in Ukraine: results from a clustered randomised trial. Lancet HIV 2016, Online first (in press).

* Randomised trial demonstrating the value of peer-led intervention in reducing HIV incidence among PWID in Eastern Europe

43. UNICEF: UNICEF Ukraine Country Office Humanitarian Situation Report, July 2016. . Edited by; 2016. 
44. Owczarzak J, Karelin M, Phillips SD. A view from the frontlines in Slavyansk, Ukraine: HIV prevention, drug treatment, and help for people who use drugs in a conflict zone. Int J Drug Policy 2015, 26:6-7.

45. Filippovych S. Impact of armed conflicts and warfare on opioid substitution treatment in Ukraine: responding to emergency needs. Int J Drug Policy 2015, 26:3-5.

46. Hope VD, Eramova I, Capurro D, Donoghoe MC. Prevalence and estimation of hepatitis B and C infections in the WHO European Region: a review of data focusing on the countries outside the European Union and the European Free Trade Association. Epidemiol Infect 2014, $142: 270-286$.

47. Gower E, Estes C, Blach S, et al. Global epidemiology and genotype distribution of the hepatitis C virus infection. J Hepatol 2014, 61:S45-57.

48. Stanaway JD, Flaxman AD, Naghavi M, et al. The global burden of viral hepatitis from 1990 to 2013: findings from the Global Burden of Disease Study 2013. Lancet 2016.

** This is first formal estimation of the total burden of viral hepatitis using the Global Burden of Disease Study approach, which showed a substantial increase in deaths and disability from 1990 to 2013. HCV accounted for the biggest increase in DALYs. The analysis presents powerful evidence that viral hepatitis, including $\mathrm{HCV}$, requires a stronger response on the country, national and international levels.

49. Messina JP, Humphreys I, Flaxman A, et al. Global distribution and prevalence of hepatitis C virus genotypes. Hepatology 2015, 61:77-87.

50. Mukomolov S, Trifonova G, Levakova I, et al. Hepatitis C in the Russian Federation: challenges and future directions. Hepat Med 2016, 8:51-60.

51. Luhmann N, Champagnat J, Golovin S, et al. Access to hepatitis C treatment for people who inject drugs in low and middle income settings: Evidence from 5 countries in Eastern Europe and Asia. Int J Drug Policy 2015, 26:1081-1087. 
* This systematic review and internet survey provides important data on the burden of HCV disease and treatment access in Georgia, Ukraine and Russia.

52. Dolan K, Wirtz AL, Moazen B, et al. Global burden of HIV, viral hepatitis, and tuberculosis in prisoners and detainees. Lancet 2016.

53. Zohrabyan L, Johnston L, Scutelniciuc O, et al. HIV, hepatitis and syphilis prevalence and correlates of condom use during anal sex among men who have sex with men in the Republic of Moldova. Int J STD AIDS 2013, 24:357-364.

54. Maticic M, Videcnik Zorman J, Gregorcic S, et al. Are there national strategies, plans and guidelines for the treatment of hepatitis $C$ in people who inject drugs? A survey of 33 European countries. BMC Infect Dis 2014, 14 Suppl 6:S14.

55. Martin NK, Vickerman P, Brew IF, et al. Is increased hepatitis C virus case-finding combined with current or 8-week to 12-week direct-acting antiviral therapy cost-effective in UK prisons? A prevention benefit analysis. Hepatology 2016, 63:1796-1808.

56. Martin NK, Vickerman P, Grebely J, et al. Hepatitis C virus treatment for prevention among people who inject drugs: Modeling treatment scale-up in the age of direct-acting antivirals. Hepatology 2013, 58:1598-1609.

57. Platt L, Easterbrook P, Gower E, et al. Prevalence and burden of HCV co-infection in people living with HIV: a global systematic review and meta-analysis. Lancet Infect Dis 2016, 16:797-808.

58. Aebi-Popp K, Bailey H, Malyuta R, et al. High prevalence of herpes simplex virus (HSV)- type 2 coinfection among HIV-positive women in Ukraine, but no increased HIV mother-to-child transmission risk. BMC Pregnancy Childbirth 2016, 16:94.

59. Taylor LE, Swan T, Matthews GV. Management of hepatitis C virus/HIV coinfection among people who use drugs in the era of direct-acting antiviral-based therapy. Clin Infect Dis 2013, 57 Suppl 2:S118-124.

60. Turkova A, Giacomet V, Goetghebuer T, et al. HCV treatment in children and young adults with HIV/HCV co-infection in Europe. J Virus Erad 2015, 1:179-184. 
61. Filippovych S. Introduction of Sofosbuvir based HCV treatment in Ukraine. . In European HIV Hepatitis C Co-infection (EHHC) conference. 10 - 11 December 2015. Edited by. London, UK: BHIVA; 2015.

62. Kubanova AA, Melekhina LE, Kubanov AA, Bogdanova EV. Syphilis incidence in the Russian Federation 2004-2013. Vestnik Dermatologii i Venerologii 2014, 5:8.

63. European Centre of Disease Control. Annual epidemiological report 2016. Edited by. Stockholm; 2016. [ECDC (Series Editor):

64. Khairullin R, Vorobyev D, Obukhov A, et al. Syphilis epidemiology in 1994-2013, molecular epidemiological strain typing and determination of macrolide resistance in Treponema pallidum in 2013-2014 in Tuva Republic, Russia. APMIS 2016, 124:595-602.

65. Grillova L, Petrosova H, Mikalova L, et al. Molecular typing of Treponema pallidum in the Czech Republic during 2011 to 2013: increased prevalence of identified genotypes and of isolates with macrolide resistance. J Clin Microbiol 2014, 52:3693-3700.

66. Grillova L, Mikalova L, Zakoucka H, Zidlicka J, Smajs D. [Macrolide resistance in Treponema pallidum subsp. pallidum in the Czech Republic and in other countries]. Epidemiol Mikrobiol Imunol 2015, 64:4-10.

67. Tipple C, Taylor GP: Syphilis testing, typing, and treatment follow-up: a new era for an old disease. Curr Opin Infect Dis 2015, 28:53-60.

68. WHO Europe. Strengthening of STI surveillance in the Republic of Moldova, Report on a mission 11-15 March 2013. Edited by. Copenhagen; 2013. [Europe W (Series Editor):

69. Svecova D, Part M, Luha J: Increasing trend in syphilis. Bratis/ Lek Listy 2015, 116:596-600.

70. Georgia National Centre for Disease Control and Public Health: Georgia Global AIDS Response Progress Report, 2014. Edited by. Geneva; 2014. [UNAIDS (Series Editor):

71. Vucetic D, Kecman G, Ilic V, Balint B. Blood donors' positivity for transfusion-transmissible infections: the Serbian Military Medical Academy experience. Blood Transfus 2015, 13:569575. 
72. Manea E, Jipa R, Niculescu I, et al. Co-infections and co-morbidities among injecting drug users versus sexually infected patients in Bucharest. J Int AIDS Soc 2014, 17:19665.

73. Boyko A, DiCarlo M, Doroshenko O, et al. HIV Epidemic Among Key Populations in Ukraine: Review of Secondary Data. Edited by. Kyiv, Ukraine; 2013.

74. El-Bassel N, Gilbert L, Terlikbayeva A, et al. HIV among injection drug users and their intimate partners in Almaty, Kazakhstan. AIDS Behav 2013, 17:2490-2500.

75. Wijesooriya NS, Rochat RW, Kamb ML, et al. Global burden of maternal and congenital syphilis in 2008 and 2012: a health systems modelling study. Lancet Glob Health 2016, 4:e525-533.

76. WHO Europe: Progress and challenges towards achieving the elimination of mother-to-child transmission of HIV and congenital syphilis in Europe and Central Asia. Consultation report 21-23 April 2015, Astana, Kazakhstan. Edited by. Copenhagen; 2015. [Europe W (Series Editor):

77. World Health Organization: WHO validates elimination of mother-to-child transmission of HIV and syphilis in Armenia, Belarus and the Republic of Moldova. Edited by. Copenhagen: WHO; 2016. 